\title{
Genetic and molecular origins of colorectal Cancer among the Iranians: an update
}

\author{
Mohammad Reza Abbaszadegan ${ }^{1}$ and Meysam Moghbeli ${ }^{2^{*}}$ (D)
}

\begin{abstract}
Background: Colorectal cancer (CRC) is one the leading causes of cancer related deaths among Iranians. Despite the various progresses in new therapeutic methods, it has still a low rate of survival. This high ratio of mortality is mainly related to the late diagnosis, in which the patients refer for treatment in advanced stages of tumor.

Main body: colorectal cancer progression is largely associated with molecular and genetic bases. Although Iran has a high ratio of CRC mortality, there is not an efficient genetic panel for detection and prognosis. Therefore, it is critical to introduce new diagnostic markers with ability to detect in early stages.

Conclusion: Present review summarizes all of the genetic and epigenetic factors which are reported in CRC until now among the Iranian patients to pave the way of incorporation of new ethnic specific markers into the clinical practice and development of new targeted therapeutic methods.
\end{abstract}

Keywords: Colorectal Cancer, Marker, Diagnosis, Iran, Genetic

\section{Background}

Colorectal carcinoma $(\mathrm{CRC})$ is one of the leading causes of cancer related deaths among Iranians with age-adjusted rates of 8.2 and 7.0 per 100,000 populations for men and women, respectively [1]. It was reported that there is a noticeable increase in the incidence of colorectal cancer among young Iranians [2]. Various factors are involved in individual's susceptibility for the CRC including environmental factors and genetic predisposition [3]. Cancer is a multi-step process associated with accumulation of genetic and epigenetic alterations [4]. Gene mutations generate the genome instability via disruption of the normal epigenetic patterns [5]. Regarding the high survival ratios among the CRC cases who are diagnosed in the early stages of CRC, it is a critical requirement to find new non-invasive biomarkers to detect the CRC in the early stages [6]. Moreover, personalized medicine is also trying to design the chemotherapy based on genetic and epigenetic patterns of cancer in every patient [7]. Mutated genes are mostly oncogenes, tumor suppressor genes, and DNA repair factors which are involved in genome instability. Various processes are

\footnotetext{
*Correspondence: moghbelim@mums.ac.ir; Meysam_moghbeli@yahoo.com ${ }^{2}$ Department of Modern Sciences and Technologies, Faculty of Medicine, Mashhad University of Medical Sciences, Mashhad, Iran

Full list of author information is available at the end of the article
}

involved in epigenetics such as DNA methylation and histone modification. Epigenetic mutations alter the gene expression without any change in DNA sequence and can result to inactivation and activation of tumor suppressor and oncogenes, respectively. There is not any single universal molecular prognostic and diagnostic marker. Regarding the role of ethnicity on prevalence of $\mathrm{CRC}$, it is believed that the different races have probably different genetic and epigenetic patterns of tumorigenesis [8]. Therefore, in present review we are going to summarize all of the 60 epigenetic and genetic aberrations which are reported until now among Iranian CRC patients (Table.1) (Fig. 1) to pave the way of designing an ethnic specific panel of diagnostic and prognostic markers in our country.

\section{Main text}

Intracellular defense systems

Glutathione S-transferases (GSTs) are involved in detoxification of carcinogens and are expressed in many tissues such as gastrointestinal tracts [9]. GSTs are belonged to the phase II metabolic enzymes which have critical roles in cellular detoxification. Phase I (activation) and phase II (conjugation) enzymes are known as the most important factors involved in metabolization of carcinogens $[10,11]$. GSTs over activity was observed in 
Table 1 All of the involved markers in CRC susceptibility among the Iranian patients

\begin{tabular}{|c|c|c|c|c|}
\hline STUDY (ET AL) & Year & Gene & population & Results \\
\hline Nomani [14] & 2005 & GST & $\begin{array}{l}39 \text { controls } \\
60 \text { patients }\end{array}$ & Over activity in tumors \\
\hline Ebrahimkhani [15] & 2012 & GSTT1 & $\begin{array}{l}100 \text { controls } \\
100 \text { patients }\end{array}$ & Polymorphism was correlated with CRC risk \\
\hline Jamhiri [16] & 2017 & SOD1 & $\begin{array}{l}239 \text { controls } \\
204 \text { patients }\end{array}$ & Polymorphism was correlated with CRC risk \\
\hline Mokarram [19] & 2015 & UBE2Q1 & $\begin{array}{l}50 \text { controls } \\
60 \text { patients }\end{array}$ & Hyper Methylation \\
\hline Mokarram [19] & 2015 & UBE2Q2 & $\begin{array}{l}50 \text { controls } \\
60 \text { patients }\end{array}$ & Un methylation and stage of tumor \\
\hline Amirghofran [22] & 2009 & TGFB1 & $\begin{array}{l}138 \text { controls } \\
134 \text { patients }\end{array}$ & Polymorphism was correlated with CRC risk \\
\hline Damavand [24] & 2015 & SMAD7 & $\begin{array}{l}253 \text { controls } \\
234 \text { patients }\end{array}$ & Polymorphism was correlated with CRC risk \\
\hline Naghibalhossaini [29] & 2012 & AXIN2 & $\begin{array}{l}170 \text { controls } \\
112 \text { patients }\end{array}$ & Methylation with stage and sex \\
\hline Samaei [30] & 2014 & $\begin{array}{l}\text { APC, AXIN2, DKK3, SFRP2, } \\
4,5, \text { WIF1, and WNT5a }\end{array}$ & $125 \mathrm{~N} / \mathrm{T}^{\mathrm{a}}$ & Methylation \\
\hline Naini [31] & 2016 & SFRP2 & $\begin{array}{l}25 \text { controls } \\
48 \text { polyps }\end{array}$ & Hyper Methylation as precancerous marker \\
\hline Nemati [34] & 2015 & IL-17A & $\begin{array}{l}203 \text { controls } \\
202 \text { patients }\end{array}$ & Polymorphism was correlated with CRC risk \\
\hline Azimzadeh [38] & 2011 & IL-16 & $\begin{array}{l}405 \text { controls } \\
260 \text { patients }\end{array}$ & Polymorphism was correlated with CRC risk \\
\hline Al-Samadi [39] & 2016 & IL-17F & 10 tumors & Under expression in tumors \\
\hline Ahangari [42] & 2014 & NOD2 & $\begin{array}{l}88 \text { controls } \\
88 \text { patients }\end{array}$ & Polymorphism was correlated with CRC risk \\
\hline Azimzadeh [43] & 2013 & CD86 & $\begin{array}{l}150 \text { controls } \\
150 \text { patients }\end{array}$ & Polymorphism was correlated with CRC risk \\
\hline Abtahi [44] & 2017 & $\mathrm{IL}-10$ & $\begin{array}{l}30 \text { controls } \\
58 \text { patients }\end{array}$ & Lower levels in CRC patients \\
\hline Habibollahi [49] & 2010 & COX2, iNOS & 17 patients & Correlation with lymph node metastasis \\
\hline Hadinia [52] & 2007 & CTLA4 & $\begin{array}{l}190 \text { controls } \\
109 \text { patients }\end{array}$ & Polymorphism was correlated with CRC risk \\
\hline Shafaei [53] & 2013 & CD166 & $121 \mathrm{~N} / \mathrm{T}$ & Correlation with tumor location \\
\hline Mahmoudi [56] & 2016 & ADIPOQ, ADIPOR1 & $\begin{array}{l}339 \text { controls } \\
261 \text { patients }\end{array}$ & Polymorphism was correlated with CRC risk \\
\hline Motlagh [58] & 2007 & EGFR & $34 \mathrm{~N} / \mathrm{T}$ & Marker of preoperative therapy response \\
\hline Tavangar [59] & 2005 & HER2 & $55 \mathrm{~N} / \mathrm{T}$ & Correlation with tumor size, stage, differentiation \\
\hline Orang [61] & 2014 & STYK1/NOK & $40 \mathrm{~N} / \mathrm{T}$ & Correlation with tumor size, stage \\
\hline Tavakoli Koudehi [63] & 2018 & AKAP4 & $62 \mathrm{~N} / \mathrm{T}$ & Correlation with liver metastasis in CRC patients \\
\hline Hamzehzadeh [65] & 2018 & KRAS & 87 patients & Mutation \\
\hline Koochak [68] & 2016 & KRAS & 1000 patients & Correlation with age, tumor type \\
\hline Omidifar [69] & 2015 & KRAS & 100 patients & Mutation \\
\hline Ghavam-Nasiri [71] & 2007 & P53 & 100 patients & Correlation with stage \\
\hline Asadi [74] & 2018 & CASPASE3 & $50 \mathrm{~N} / \mathrm{T}$ & Under expression \\
\hline Golmohammadi [75] & 2013 & P53 & 61 patients & Correlation with distal tumors, sex, survival \\
\hline Moossavi [77] & 2018 & VDR & $\begin{array}{l}100 \text { controls } \\
100 \text { patients }\end{array}$ & Polymorphism was correlated with CRC risk \\
\hline Mahmoudi [78] & 2010 & VDR & $\begin{array}{l}180 \text { controls } \\
160 \text { patients }\end{array}$ & Polymorphism was correlated with CRC risk \\
\hline
\end{tabular}


Table 1 All of the involved markers in CRC susceptibility among the Iranian patients (Continued)

\begin{tabular}{|c|c|c|c|c|}
\hline STUDY (ET AL) & Year & Gene & population & Results \\
\hline Mahmoudi [82] & 2016 & IRS1 & $\begin{array}{l}438 \text { controls } \\
312 \text { patients }\end{array}$ & Polymorphism was correlated with CRC risk \\
\hline Karimi Mazraehshah [86] & 2018 & miR-200c, BMI1 & $\begin{array}{l}38 \text { controls } \\
38 \text { patients }\end{array}$ & Under an over expression, respectively \\
\hline Orang [90] & 2014 & miR-205 & $36 \mathrm{~N} / \mathrm{T}$ & Correlation with lymph node metastasis, stage \\
\hline Basati [91] & 2014 & $\operatorname{miR}-21$ & $\begin{array}{l}40 \text { controls } \\
40 \text { patients }\end{array}$ & Correlation with stage \\
\hline Bastaminejad [92] & 2017 & miR-21 & $\begin{array}{l}40 \text { controls } \\
40 \text { patients }\end{array}$ & Correlation with stage \\
\hline Basati [95] & 2016 & miR-194 & $\begin{array}{l}55 \text { controls } \\
55 \text { patients }\end{array}$ & Correlation with stage \\
\hline Eslamizadeh [105] & 2018 & miR-135b, 20a, 31, 21 & $\begin{array}{l}32 \text { controls } \\
74 \text { patients }\end{array}$ & Increased levels in CRC patients \\
\hline Montazer Haghighi [107] & 2009 & MMR & $\begin{array}{l}248 \text { controls } \\
592 \text { patients }\end{array}$ & Novel mutations in PMS2 and MLH1 \\
\hline Shahmoradi [108] & 2012 & hMLH1 & 20 patients & Novel mutations \\
\hline Moghbeli [110] & 2011 & MMR & $67 \mathrm{~N} / \mathrm{T}$ & $\begin{array}{l}\text { MSI was correlated with location, stage, lymph } \\
\text { node metastasis }\end{array}$ \\
\hline Faghani [111] & 2012 & MMR & $96 \mathrm{~N} / \mathrm{T}$ & MSI was correlated with location \\
\hline Nazemalhosseini Mojarad [112] & 2016 & MMR & $158 \mathrm{~N} / \mathrm{T}$ & MSI was correlated with differentiation, stage, sex \\
\hline Brim [113] & 2008 & MMR & 53 patients & MSI was correlated with differentiation \\
\hline Khatami [114] & 2009 & MGMT & $\begin{array}{l}213 \text { controls } \\
208 \text { patients }\end{array}$ & Polymorphism was correlated with CRC risk \\
\hline Farzanehfar [115] & 2013 & MGMT & $40 \mathrm{~N} / \mathrm{T}$ & Methylation \\
\hline Nemati [117] & 2018 & HDAC3 & $48 \mathrm{~N} / \mathrm{T}$ & Correlation with stage, differentiation \\
\hline Ayoubi [121] & 2017 & $\mathrm{H} 3.3 \mathrm{~B}$ & $36 \mathrm{~N} / \mathrm{T}$ & Correlation with stage, lymph node \\
\hline Mohammed [125] & 2015 & tRNA $A^{\operatorname{Leu}(C U N)}$ & $\begin{array}{l}100 \text { controls } \\
30 \text { patients }\end{array}$ & Mutation \\
\hline Haghighi [128] & 2008 & MTHFR & $\begin{array}{l}239 \text { controls } \\
227 \text { patients }\end{array}$ & Polymorphism was correlated with CRC risk \\
\hline Naghibalhossaini [131] & 2010 & MTHFR & $\begin{array}{l}231 \text { controls } \\
175 \text { patients }\end{array}$ & Polymorphism was correlated with CRC risk \\
\hline Samanian [136] & 2011 & MDR1 & $\begin{array}{l}60 \text { controls } \\
60 \text { patients }\end{array}$ & Correlation with grade \\
\hline Khedri [137] & 2011 & MDR1 & $\begin{array}{l}137 \text { controls } \\
118 \text { patients }\end{array}$ & Correlation with stage \\
\hline Ardalan Khales [138] & 2015 & SALL4 & $111 \mathrm{~N} / \mathrm{T}$ & Correlation with grade, depth of invasion \\
\hline Raeisossadati [143] & 2014 & DPPA2, HIWI & $46 \mathrm{~N} / \mathrm{T}$ & Correlation with stage, lymph node metastasis \\
\hline Mirzaei [146] & 2015 & LGR5, DCLK1 & $\begin{array}{l}58 \text { controls } \\
58 \text { patients }\end{array}$ & Correlation with stage \\
\hline Niknami [149] & 2017 & FIBRONECTIN & 45 patients & Correlation with grade \\
\hline Hosseini [150] & 2018 & NEBL & $67 \mathrm{~N} / \mathrm{T}$ & Correlation with lymph node metastasis \\
\hline Behrouz Sharif [153] & 2016 & SEPT9 & $45 \mathrm{~N} / \mathrm{T}$ & Methylation \\
\hline Raeisossadati [154] & 2011 & CEA, TEM8 & $\begin{array}{l}40 \text { controls } \\
40 \text { patients }\end{array}$ & Over expression in CRC patients \\
\hline
\end{tabular}

${ }^{a}$ Tumor tissues and normal margins

chemotherapeutic resistant tumors against the alkylating agents [12, 13]. GST activity in plasma and tissue were assessed in Iranian CRC cases. There was a significant GSTs over activity in tumor compared with normal margins. This strong correlation supported the plasma GST activity as a non-invasive biomarker [14]. GSTM1, P1, T1, and CYP2E1 polymorphisms were also assessed among Iranian CRC subjects. They reported that there 


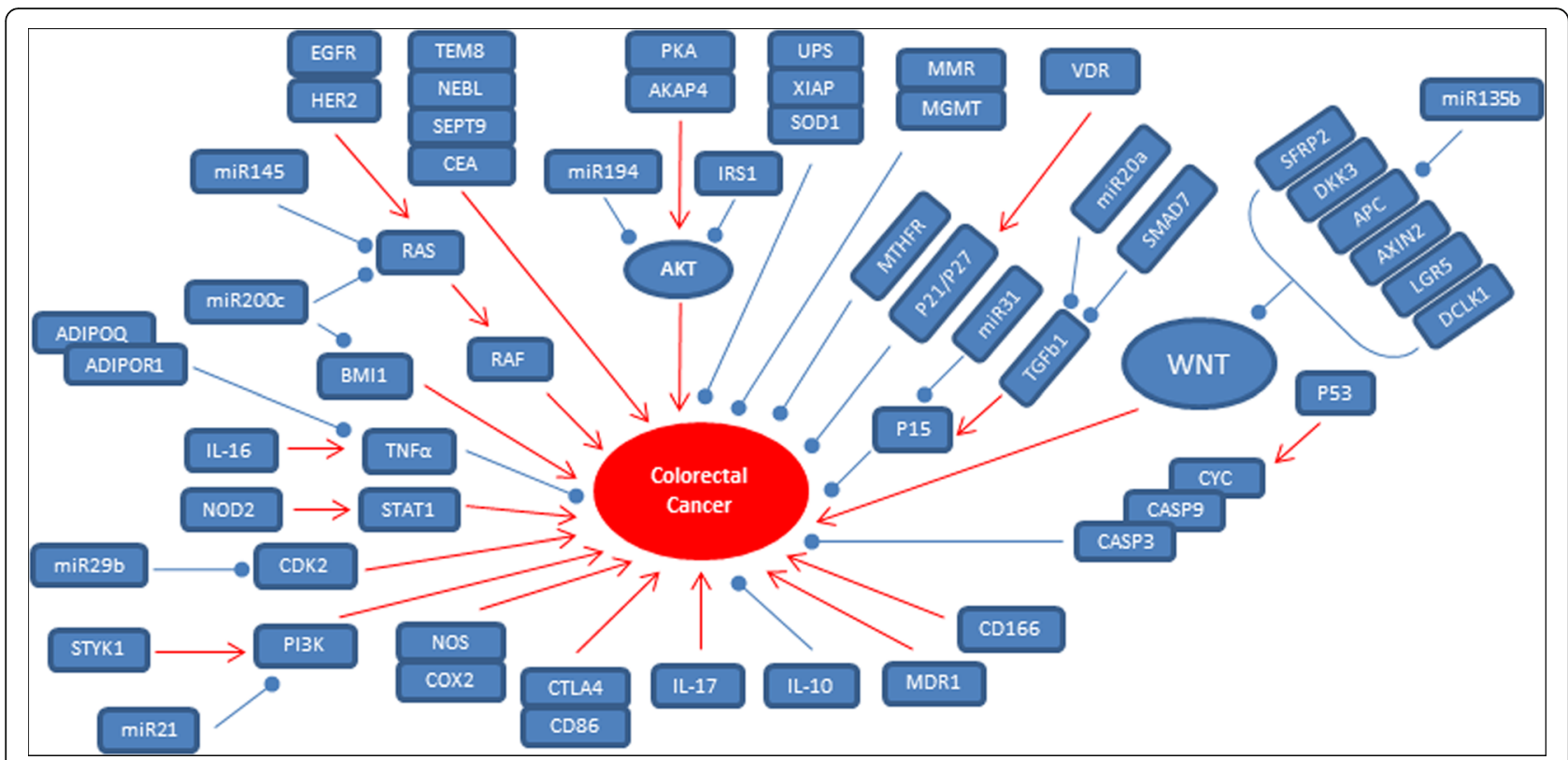

Fig. 1 all of the interactions and signaling pathways of reported markers which are involved in CRC progression among Iranian patients.

was a strong correlation between GSTT1 polymorphism and CRC [15]. Superoxide dismutase (SOD) and catalase are the main protective enzymes against reactive oxygen species. SODs convert the superoxide into hydrogen peroxide, subsequently the catalase is responsible for the hydrogen peroxidase detoxification through converting that into the water and oxygen. Therefore, a group have assessed the correlation between SOD1 A251G and CAT C-262 T polymorphisms and CRC susceptibility among the Iranian population. They observed that the SOD1 G allele was correlated with a higher risk of CRC. Therefore, polymorphisms in antioxidant enzymes increase risk of CRC through the decreased antioxidant capacity [16]. Beside the toxic compounds and ROS, abnormal and defective proteins can be also damaging for the cells, therefore it will be required for the cells to eliminate such abnormal proteins. Ubiquitin-proteasome system (UPS) regulates various cellular processes such as cell differentiation, proliferation, and apoptosis [17]. It was reported that deregulation of ubiquitin-proteasome can be involved in tumor progression through the modulation of growth factors stability. UBE2Q1, 2 are belonged to the E2 ubiquitin-conjugating enzyme family [18]. Methylation status of UBE2Q1 and UBE2Q2 were assessed in a group of Iranian CRC cases. UBE2Q2 was highly un-methylated in distal and advanced stage tumors suggesting the UBE2Q2 as a probable oncogene during the CRC progression. It was observed that the UBE2Q1 hypermethylation and UBE2Q2 hypomethylation as tumor suppressor and oncogene respectively can be associated with CRC progression [19].
TGF-b and WNT signaling pathways

Transforming growth factor $\mathrm{b}$ (TGF-b) act as a tumor suppressor via cell proliferation arrest and apoptosis induction during early stages of tumor progression [20]. TGF-b1 binding with receptor type II (TGF-bRII), results to phosphorylation of the receptor type I (TGF-bRI). This interactions finally activates and transfers the SMADs into the nucleus, resulting in the transcriptional regulation of target genes which are related to the cell proliferation [21]. Role of TGFB1 gene -509 $\mathrm{C} / \mathrm{T}$ polymorphism in risk of $\mathrm{CRC}$ was evaluated in a group of Iranian patients. They showed that the cases with the TGFB1 $509 \mathrm{~T}$ allele can be at a lower risk of $\mathrm{CRC}$ in comparison with the cases harboring $509 \mathrm{C}$ allele. This study highlighted role of this cytokine in suppression of CRC in which the $509 \mathrm{~T}$ allele has probably a protective role during the tumor progression [22]. SMAD7 is an inhibitor of the TGF- $\beta$ which functions as an oncogene through the suppression of TGF- $\beta$ signaling [23]. It was shown that there was a significant difference between the rs4464148 AG frequency of SMAD7 in the CRC and control groups. It was demonstrated that the allele $\mathrm{T}$ at rs12953717 of SMAD7 can be introduced as a risk factor of CRC among Iranian patients [24]. Canonical Wnt/b-catenin is one of the critical pathways during the tumorigenesis in which the unphosphorylated and activated b-catenin enters into nucleus and activates the LEF/TCF/PYGO2 transcriptional complex [25]. GSK3b, AXIN, and APC are the components of a complex which is responsible for the regulation of b-catenin. This complex phosphorylates and induces the 
degradation of b-catenin via the proteasome in the absence of WNT signals [26]. Regarding the presence of APC mutation in more than $80 \%$ of CRCs, aberrant WNT signaling pathway has a critical role in CRC progression $[27,28]$. It was observed that the 7 and $12 \%$ of a group of 112 Iranian CRC patients had AXIN2 and APC promoter methylation. AXIN2 promoter methylation was mainly observed in stage I tumors and females [29]. Another group also examined the promoter methylation status of several WNT inhibitors among 125 Iranian CRC patients. They observed the APC, AXIN2, DKK3, SFRP2, 4, 5, WIF1, and WNT5a promoter methylation in $35.2,32.8,40,46.4,28.8,26.4,41.6,22.4 \%$ of tumor samples, respectively [30]. It was reported that the hypermethylation of APC1A and SFRP2 promoter sequences as the WNT target genes are also correlated with polyp progression. Therefore, hypermethylation of serum SFRP2 can be suggested as a sensitive precancerous marker [31].

\section{Inflammatory factors}

The cell microenvironment and tissue homeostasis and repair can be modulated by inflammatory responses [32]. Adaptive and innate immune systems have important roles in cancer. IL-17 is an inflammatory cytokine secreted by Th17 cells and stimulates the Macrophages and Neutrophils to produce the inflammatory factors in human malignancies [33]. Frequencies of IL-17 SNPs were assessed in CRC tumors and serum levels of IL-17 were compared in patients and healthy controls. It was found that the TT genotype and T allele were decreased in comparison with the TC genotype and $\mathrm{C}$ allele among Iranian CRC patients. There was a significant correlation between IL-17F TT genotype and well differentiation. There was also a significant correlation between the AG genotype of IL-17A G197A SNP and higher risk of colorectal cancer. In contrast with the IL-17F, IL-17A serum concentrations were significantly increased in CRC compared with healthy cases. Therefore, IL-17A is a tumor progression cytokine and can be efficiently introduced in targeted therapy of CRC patients [34]. IL-16 is a chronic inflammation cytokine mediating tissue specific or systemic inflammation $[35,36]$. It was observed that the IL-16 up regulates the TNF- $\alpha$ as an important factor in apoptosis and cell survival [37]. Single nucleotide polymorphisms in promoter and exons of IL-16 were screened to assess the frequency of genotypes in Iranian $\mathrm{CRC}$ and healthy cases. The results suggested a correlation between rs11556218 $\mathrm{T}>\mathrm{G}$ and rs4778889 T/C polymorphisms and risk of CRC among a sub population of Iranian patients [38]. Expression of IL-17B, C, E, and $\mathrm{F}$ were also examined among Iranian sporadic CRC cases. Although the IL-17B was increased, IL-17C showed a grade-linked expression pattern and IL-17E remained unchanged in CRC patients. IL-17F under expression was observed in tumors in comparison with the normal samples [39]. NOD2 protein is a regulator of chronic inflammatory that is expressed in monocytes and macrophages. It functions as a sensor of lipopolysaccharides and peptidoglycans to induce the (NF)-jB and STAT1 transcription factors which are associated with inflammation-related tumor progression [40, 41]. Correlation between rs3135500 (30UTR SNP) of NOD2 and CRC susceptibility was evaluated among the Iranian population. It seems that the rs 3135500 SNP is involved in deregulation of NOD2 through changing the mRNAmiRNA interaction. There was a significant correlation between AA genotype of rs 3135500 and increased risk of CRC in Iranian population [42]. CD86 is expressed by immune cells and is associated with inflammation related malignancies and cancer susceptibility. The 3'UTR + $237 \mathrm{G} / \mathrm{C}$ polymorphism of CD86 was assessed among 300 Iranian CRC cases and showed a strong correlation between rs17281995 polymorphism and risk of CRC [43]. IL-10 as an anti-inflammatory cytokine is commonly secreted by type 1 regulatory T cells and can be an oncogene or tumor suppressor based on microenvironment condition. A case-control study showed that there was significantly lower serum levels of IL-10 in Iranian CRC cases compared with controls which cause an aberrant innate immune reaction and tumor cell ignorance by adaptive immune. Moreover, the cases with poor prognosis had higher levels of IL-10 compared with the other cases [44]. Nitric oxide (NO) is involved in DNA damage and apoptosis inhibition [45, 46]. Its production is related with three isoforms of nitric oxide synthase (NOS) including endothelial (eNOS), neuronal (nNOS), and inducible (iNOS). eNOS and nNOS activations are calcium dependent [47], whereas, iNOS is related to the cytokines and has a calcium independent function. It has been shown that the NO is involved in prostaglandin biosynthesis through the COX-2 activation during inflammation process [48]. It was shown that the COX2 and iNOS protein co-expressions were observed in epithelial tumor cells. The cases with lymph node metastasis showed higher levels of COX2 and iNOS protein expressions. Therefore, there was a direct correlation between iNOS and COX2 in advanced stage tumors among the Iranian CRC subjects [49]. Cytotoxic T-lymphocyte antigen-4 (CTLA-4) is one of the critical factors in immune responses against different antigens and is expressed by activated $\mathrm{T}$ cells $[50,51]$. It was shown that the TACG haplotype of CTLA-4 gene can be associated with high susceptibility to CRC among Iranian population [52]. Role of CD166 was studied in Iranian CRC cases using an immunohistochemical method, and it was shown that $71.1,34.7$, and $34.7 \%$ of cases were positive in cytoplasmic, membranous, and 
simultaneous expressions, respectively. Non-mucinous types had higher levels of cytoplasmic CD166 expression. Moreover, there was an association between tumor location and CD166 expression in which the tumors in right colon were related with CD166 membranous expression [53]. Adiponectin is mainly produced by adipose tissue and has anti-inflammatory and anti-proliferative functions [54, 55]. ADIPOQ (rs2241766) and ADIPOR1 (rs2275738) gene variants were assessed among Iranian CRC cases. It was reported that there was a correlation between ADIPOQ rs2241766 "G" allele and decreased risk of CRC among obese patients. Moreover, the cases with ADIPOR1 rs2275738 "CC + CT" had about $49 \%$ higher risk of CRC in comparison with the "TT" genotype [56].

\section{Kinases and growth factors}

EGFR is a tyrosine kinase and transmembrane glycoprotein which is dimerized following the activation and exerts an intrinsic tyrosine kinase activity. Subsequently, this factor triggers a cytoplasmic cascade toward the cell proliferation and differentiation [57]. It was observed that the expression rates was $41 \%$ among a group of Iranian CRC patients with pathologic response of $59 \%$. They indicated that EGFR expression can be used as an important marker of pathologic response to preoperative treatment in which the EGFR expression was related with a lack of pathologic response [58]. Another group also reported a HER2 over expression in $21.8 \%$ of Iranian colorectal cancer patients and there was significant correlations between HER2 over expression and tumor size and advanced stages. Moreover, the HER2 over expression was more frequent in moderate and poorly differentiated tumors [59]. STYK1/ NOK is a tyrosine kinase receptor that can be activated in a non-specific status due to lacks extracellular domain [60]. Levels of STYK1/NOK expression were evaluated in a group of Iranian CRC cases. It was shown that there was a noticeable STYK1/NOK over expression in CRC tissues and a significant correlation between STYK1/NOK over expression and tumor size. They observed the high levels of STYK1/NOK expression in the early clinical stages of CRC [61]. Although, Cancer-Testis antigens (CTAs) are expressed in normal testis, their aberrant expression is observed in different tumors [62]. AKAP4 is one of the members of CTA family which binds to protein kinase A (PKA) to connect that to the specific cellular locations. Levels of AKAP4 expression were assessed in Iranian CRC patients which showed a significant correlation between AKAP4 expression and liver metastasis in CRC cases. AKAP4 was expressed in normal testis and CRC tissues but not in normal margins, introducing that as a diagnostic CRC marker [63]. Between 30 and $40 \%$ of CRC tumors harbor the mutated KRAS gene [64]. The
$\mathrm{N}$-Ras is a guanosine triphosphatase membrane protein which is observed mutated in $1-6 \%$ of CRC cases. Frequency of KRAS mutations was assessed in 87 Iranian CRC patients. They showed a $28.7 \%$ of KRAS mutation that was in the range of other Asian and western countries. They showed a similarity in the KRAS hotspot mutations between Iranian and other countries CRC patients [65]. The KRAS activates BRAF through a signal transduction cascade including EGFR and MAPK $[66,67]$. Mutational analysis of KRAS and BRAF genes were performed in a group of Iranians with metastatic CRC using Pyrosequencing method. KRAS mutation was observed in $33.6 \%$ of CRC cases, which involves mutations at codon 12 and 13 . There was a significant correlation between KRAS mutations and older ages and tumor type (non-mucinous) [68]. Incidence of mutation in codons 12 and 13 of KRAS was screened by another group among Iranian CRC subjects, showed that the codon 13 mutations had lower frequencies compared with codon 12 ( $8 \%$ vs. 24\%). Moreover, up to $32 \%$ of cases harbors mutations in both of codon 12 or 13 [69].

\section{Apoptosis}

The p53 tumor-suppressor gene has an important role in cell cycle regulation following the DNA damage. Moreover, p53 as a transcription factor is involved in regulation of more than 100 different factors [70]. It stimulates transcription of factors involving in the cell cycle arrest and apoptosis. Levels of p53 protein expression was assessed in a group of Iranian CRC cases. They observed higher percentage of p53-positive expression in advanced stages, introducing that as a genetic marker for tumor relapse prediction and response to chemotherapy in Iranian CRC cases [71]. Caspase 8 is one of the components of extrinsic apoptosis pathway. Although the intrinsic pathway is related to the cytochrome $\mathrm{c}$ release from mitochondria and caspase 9 activation, both of intrinsic and extrinsic pathways are merged in activation of caspase 3 [72, 73]. It has been shown that there was a caspase 3 under expression in tumor compared with normal CRC samples. Moreover, aberrant caspase 8 and 9 mRNA expressions were also observed in CRC in comparison with normal margins [74]. Mutational analysis of exons 5 and 6 in p53 were also studied in a subpopulation of Iranian CRC patients. Twenty one point mutations including two novels were observed. There was an association between frequency of mutations and distal tumors. Moreover, females had lower mutation rates in comparison with males (13\% vs $26 \%)$, and the cases with mutated p53 had shorter survival in comparison with the none mutated cases [75].

\section{Vitamin D and insulin}

It has been reported that the vitamin $\mathrm{D}$ interaction with its receptor (VDR) is associated with CRC susceptibility 
[76]. It was observed that the ff (TT) genotype of rs2228570 can be suggested as a risk factor genotype for CRC susceptibility among a group of Iranian CRC patients [77]. Moreover, another group also reported that the VDR ApaI genotype "aa" is correlated with higher risk of CRC among a sub population of Iranian patients [78]. Insulin is involved in cell proliferation and has an anti-apoptotic role in the target tissues. Hyperinsulinemia has been proposed as an important process to link the obesity with CRC [79]. Type 2 diabetes mellitus in association with insulin resistance and obesity increase the CRC susceptibility [80]. Insulin receptor substrate 1(IRS1) has a key function in cell proliferation [81]. Association of IRS1 (rs1801278) with CRC risk was assessed and showed that the IRS1 G972R R allele and $R R+G R$ genotype have protective roles in obese Iranian CRC patients [82].

\section{MicroRNAs}

MicroRNAs are noncoding RNAs that regulate several cellular processes such as proliferation and migration. They exert their regulatory function through the mRNA degradation or translational suppression via 3 '-untranslated regions [83]. MiR-200c inhibits the cell proliferation and EMT and stimulates the chemo sensitivity and apoptosis [84, 85]. BMI1 as a components of polycomb repressive complex is involved in chromatin remodeling, cell cycle regulation, DNA repair, and self-renewal. Expression of miR-200c and BMI1 were assessed in a group of Iranian CRC cases, showing an under and over expression of miR-200c and BMI1 respectively in tumors compared with normal margins. Therefore, there was a converse correlation between miR-200c and BMI1 in which the miR-200c exerts its tumor suppressor role via BMI1 inhibition in CRC patients [86]. MiR-205 is an epithelial-specific miRNA involving in EMT and cell differentiation [87]. It functions as a tumor suppressor or oncogene depending on the targeted mRNA [88, 89]. It was observed that there was a correlation between the lower levels of miR-205 expression and lymph node metastasis. Therefore, it seems that the loss of miR-205 can be involved in advanced stages of CRC progression in which de-differentiated tumor cells migrates via an EMT process [90]. MiR-21 as an oncogene targets several important factors such as PTEN, PI3K, BTG2, FasL, and FBXO11. Serum level of miR-21 was analyzed and showed a significant elevated levels in CRC in comparison with control cases. Moreover, there was a significant correlation between serum miR-21 levels and tumor stage, suggesting this marker as an efficient prognostic factor among Iranian CRC subjects [91]. Another group also reported the elevated levels of miR-21 in stool and serum of Iranian CRC patients. It was shown that the levels of miR-21 expression in tumor cells were associated with stool and serum. There was also a significant correlation between miR-21 over expression and tumor stages of I and II. Therefore, miR-21 expression in serum and stool can be introduced as an efficient detection marker among the Iranian CRC patients [92]. MiR-29b targets several important factors such as MMP-2 and CDK2 which are important for the epithelial cell growth [93, 94]. Another group have also assessed the serum levels of miR-194 and miR-29b and observed a significant decrease in CRC compared with the control subjects. There were correlations between declined serum miR-194 and miR-29b levels and poor prognosis and tumor stage suggesting the miR-194 as a tumor suppressor in CRC cases. Therefore, serum miR-194 and miR-29b levels can be used as a non-invasive prognostic and diagnostic method among the Iranian CRC patients [95]. MiR-200c prohibits the EMT through downregulation and upregulation of ZEB1/2 and E-cadherins, respectively [96, 97]. MiR-145 exerts its tumor suppressor role via inhibition of various factors such as MYC, Kras, and SOX2 [98, 99]. MiR-135b as an oncogene also targets different tumor suppressors such as LATS1-2 and APC [100]. HIF-1 $\alpha$ and CDKN2B tumor suppressors are the targets of miR-31 [101, 102]. MiR-20a is involved in tumor progression through down regulation of several factors including Smad4, E-cadherin, and TGF- $\beta$ [103, 104]. Expression of eight miRNAs including miR-31, miR-135b, miR-133, miR-21, and miR-20a were also examined in tumor and plasma of CRC cases. The levels of miR-21, miR-31, miR-20a and miR-135b were significantly increased in both plasma and tissue of CRC cases in comparison with the control group. There were significant differences between the levels of miR-21 and miR-20a expressions and stage of tumor, in which the plasma levels of miR-21 and miR-20a showed a significant rising from the early to advanced stages of CRC. Therefore, they introduced the miR-135b, 20a, 31 and 21 as probable efficient diagnostic factors among Iranian CRC patients [105].

\section{DNA repair and microsatellite instability}

Accumulation of genetic abnormalities is one of the main reason of CRC progression. About $85 \%$ of CRCs initiate from chromosomal instability, whereas the others are associated with microsatellite instability (MSI). MSI is due to the failure of mismatch repair (MMR) system leading to aberrant replication [106]. Assessment of MMR germline mutations among the Iranian HNPCC cases showed four novel mutations in PMS2 and MLH1 [107]. Mutational analysis of hMLH1 was also performed in a sub population of Iranian HNPCC, and showed two novel frame shift mutations at exons 1 and 19. They suggested that the determination 
of hMLH1 regional mutation patterns can be helpful to design efficient preventive strategies to decrease the HNPCC mortality [108]. Standard microsatellite NCI/ ICG panel [109] was assessed in sporadic CRC patients in the northeastern Iran. MSI was observed in $43.3 \%$ of our patients and $26.9 \%$ of cases had MSI-H phenotype. MSI was correlated with right-sided and lower stage tumors whereas MSS was correlated with lymph node metastasis. MSI testing was suggested to determine effective chemotherapeutic regimen in our population [110]. Another study also used BAT-25 and BAT-26 markers to assess the correlation between MSI and sporadic CRC among the cases from northern Iran and showed a similar incidence of these markers. They showed that there was an association between tumor location and MSI-H in which $81.8 \%$ of MSI-H tumors were located in distal colon. Moreover, among MSI-H cases the distal tumors had higher rate of lymph node metastasis compared with proximal tumors $(74.2 \%$ vs. 25.8\%). Generally, metastasis ratio in MSI-H was higher than that in MSS tumors in right and left tumors [111]. The correlation between prognosis and MSI was assessed in CRC patients and showed that the MSI-H tumors were significantly correlated with poorer differentiation and stage II/III of tumors. There was also a significant correlation between MSI status and gender in which the males had a high incidence of MSI-H. In the case of stage II samples, MSI-L cases had significantly poorer survival rate in comparison with the MSI-H cases [112]. Microsatellite instability and BRAF mutational analysis in Iranian CRC population have shown 13\% of instability and $2 \%$ of BRAF mutation, respectively. MSI was more frequent in proximal tumors and MSI-H was correlated with higher tumor differentiation [113]. The O6-methylguanine DNA methyltransferase (MGMT) maintains genomic stability via alkylated DNA repair. Frequency of polymorphism in MGMT and DNMT1 were assessed in a group of Iranian CRC patients and there was significant correlations between Arg128Gln and Gly160Arg polymorphisms in MGMT and risk of CRC [114]. In another report, the MGMT promoter methylation was also evaluated using a QMSP method in a sub population of Iranian CRC cases. It was observed that the tumor tissues had significantly higher levels of MGMT methylation compared with control tissues. Therefore epigenetic inactivation of MGMT through promoter hypermethylation can be introduced as an efficient method of early detection among the Iranian CRC patients [115].

\section{Chromatin remodeling factors}

Aberrant DNA methylation and histone modifications play important roles during tumor progression. Histone acetyltransferases (HATs) induce the chromatin access and gene transcription; while, histone deacetylases (HDACs) condense the chromatin and inactivate transcription [116]. Levels of HDAC3 gene expression were assessed in a group of Iranian CRC cases showing a high expression in the tumors. There was correlation between HDAC3 over expression and advanced stages of disease and poorly differentiation. Therefore, HDAC3 can be introduced as a prognostic biomarker and efficient therapeutic target among the Iranian CRC patients [117]. Histone family including $\mathrm{H} 1, \mathrm{H} 2 \mathrm{~A}, \mathrm{H} 2 \mathrm{~B}, \mathrm{H} 3$, and $\mathrm{H} 4$ are the most important factors which are responsible for the chromatin condensation. H3.3 histone is encoded by $\mathrm{H} 3.3 \mathrm{~A}$ and $\mathrm{B}$ and overexpressed in promoter sequences and transcriptionally active regions $[118,119]$. EGFR activates the MAPK signaling pathway which induces the transcription factors such as CREB and ATF1 to regulate the H3.3B [118, 120]. Then, H3.3 histone converts the heterochromatin to euchromatin and activates the factors which are involved in tumor progression $[118,119]$. H3.3B over expression was observed in tumor compared with normal margins among a sub population of Iranian CRC subjects. There was significant correlations between levels of H3.3 expression and tumor stage III and lymph node metastasis. Therefore, H3.3B can be probably introduced as a prognostic marker in CRC [121].

\section{Mitochondrial DNA}

Mitochondria are the only organelles in eukaryotes with extra chromosomal DNA. Human mitochondria encode polypeptides and ribonucleic acids which are involved in oxidative phosphorylation. Moreover, there is a D-loop non coding region involving in regulation of replication and transcription in mitochondrial DNA. Therefore, D-loop mutations can be resulted to the accumulation of reactive oxygen species and DNA damage and tumorigenesis [122]. D-loop mutations have been screened in a group of Iranian CRC patients compared with healthy cases. They observed that there was higher frequencies of SNP in CRC patients in comparison with control group. Frequencies of eight SNPs were shown to be significantly different between CRC and control groups, introducing these SNPs as probable risk factors among CRC patient. There was also one thymine to cytosine transition at np16519 in 70\% of CRC cases [123]. Majority of mtDNA mutations have been observed in mt-tRNA genes [124]. The human mitochondrial A12308G mutation in tRNA Leu (CUN) was assessed in a sub population of Iranian CRC patients. They observed a significant higher frequency of A12308G polymorphic mutation in V-loop (tRNA ${ }^{\mathrm{Leu}(\mathrm{CUN})}$ ) among the CRC patients compared with healthy controls [125].

\section{Methylation and DNA synthesis}

Folate as the main source of methyl groups is involved in DNA repair, methylation, and synthesis. 
Methylenetetrahydrofolate reductase (MTHFR) is a key enzyme in folate metabolism and methionine production which is a methyl donor for DNA [126]. Therefore folate deficiency may results to the oncogenic DNA hypomethylation [127]. Correlation between the SNP in MTHFR and risk of CRC was assessed in a group of Iranian population, showing a converse correlation between codon G1793A and colon cancer. Their results showed an inverse correlation between MTHFR1793 genotype with colorectal cancer among Iranians [128]. Folate aberration may lead in higher DNA replication errors and chromosomal breaks via misincorporation of uracil into DNA $[129,130]$. Therefore, it has been shown that MTHFR aberration can be associated with MSI in CRC. A case-control study has been evaluated the role of C677T and A1298C polymorphisms in tumor susceptibility and MSI in a group of Iranian CRC patients. They observed that the MTHFR $677 \mathrm{~T}$ allele was strongly correlated with CRC and MSI which can be due to MMR inactivation through promoter hypermethylation [131].

\section{Drug resistance}

Chemotherapeutic treatments are the most efficient therapeutic methods, however drug resistance in many tumors is a big problem in cancer therapy [132, 133]. Multi drug resistance (MDR) is a process of drug resistance in tumor cells against a wide range of drugs [134]. The multi-drug resistance (MDR1) is belonged to the $\mathrm{ABC}$ transporters with ability of drug exclusion from the cells through an energy-dependent efflux pump activity [135]. Role of several polymorphisms in expression levels of MDR1 was evaluated among a group of Iranian CRC patients. There was a significant difference between frequency of G2677 T/A polymorphism in control and patients groups. It was shown that the GG2677 and AT 2677 genotypes were correlated with highest and lowest levels of MDR1 expression, respectively. Moreover, there was a correlation between G2677 T/A polymorphism and grade of CRC tumors [136]. Another group has also reported that there was a correlation between MDR1 polymorphism and risk of CRC among Iranian patients. They reported that the 3435TT genotype plays an important role in the early steps of CRC progression [137].

\section{Self-renewal and Cancer stem cells}

SALL4 is a zinc-finger transcription factor involving in self-renewal of stem cells. Levels of SALL4 mRNA expression have been evaluated in peripheral blood and serum of CRC cases. They showed a significant higher SALL4 copy numbers in blood and serum of CRC patients compared with normal controls. Moreover, there was significant correlations between SALL4 expression and tumor differentiation and depth of invasion. SALL4 blood copy numbers were conversely correlated with tumor depth of invasion, cases without tumor invasion into the adventitia had significantly higher levels of SALL4 copy numbers compared with patients with tumor invasion. Therefore, SALL4 can be introduced as an efficient diagnostic marker for the early detection of Iranian CRC cases [138]. DPPA2 and HIWI are also developmental factors which are associated with reprogramming and self-renewal state of stem cells $[139,140]$. DPPA2 expression is limited to the germ and pluripotent stem cells. The HIWI protein has critical roles in self-renewal and proliferation of stem cells through the regulation of several processes such as protein synthesis, RNAi mechanism, and mRNA stability $[141,142]$. We have shown the HIWI and DPPA2 mRNA over expressions in 34.8 and $26.1 \%$ of 46 Iranian CRC cases, respectively. HIWI and DPPA2 over expressions had significant correlations with advanced stages and lymph node metastasis, respectively. Moreover, there was a significant direct correlation between HIWI and DPPA2 mRNA expression in which DPPA2 probably regulates the HIWI expression in CRC [143]. Cancer stem cells (CSCs) are a sub population of tumor cells which are responsible for the drug resistance and tumor relapse [144, 145]. Therefore, targeted therapy against the CSCs can be an efficient method to overcome the tumor relapse. To evaluate the presence of CSCs in peripheral blood (PB), LGR5 and DCLK1 expressions have been assessed in blood sample of CRC patients. Levels of Lgr5 and DCLK1 in PB of CRC were higher than them in control group. Moreover, there was a significant correlation between Lgr5 and DCLK1 over expressions and advanced stages of CRC. Pre-operation chemoradiotherapy was also associated with higher levels of DCLK1 mRNA expression. Generally, they suggested the Lgr5 and DCLK1 as CSC markers among a sub population of Iranian CRC patients [146].

\section{Cell adhesion and cytoskeletal factors}

The epithelial-mesenchymal transition (EMT) is maintained through up and down-regulation of mesenchymal and adhesion factors [147]. Fibronectin is a member of extracellular matrix and is involved in cell migration, embryogenesis, and EMT [148]. It has been observed that the levels of Fibronectin mRNA expression was increased and decreased in primary and advanced tumor grades respectively in a subpopulation of Iranian CRC patients [149]. Nebulin (NEBL) is also involved in cell adhesion through interaction with thin filaments, vinculin, and paxillin which probably increase the cell migration via destabilization of focal adhesions. Levels of NEBL mRNA expression was evaluated in CRC tumors and their corresponding normal margins among Iranian 
CRC cases. It was shown that the tumor tissues had three fold increases of NEBL mRNA expression in comparison with the normal tissues. There was also a significant direct correlation between levels of NEBL mRNA expression and lymph node metastasis. Therefore, they suggested that the NEBL can be introduced as a prognostic factor among the Iranian CRC patients [150]. Septin 9 (SEPT9) is a GTP-binding protein which is involved in cytoskeletal filamentous structures [151, 152]. Promoter methylation status of SEPT9 was examined using MS-HRM assay in CRC patients. SEPT9 had significant high levels of promoter methylation in tumor compared with normal margins. They concluded that the SEPT9 methylation can be introduced as a diagnostic marker among the Iranian CRC patients [153]. Carcinoembryonic antigen (CEA) as a hemophilic cell adhesion protein has important role in embryogenesis and tumorigenesis. Tumor epithelial marker 8 (TEM-8) is also involved in cell interaction with extracellular matrix. We have shown that the mRNA levels of TEM-8 and CEA in peripheral blood of CRC patients were significantly higher than that in the control group. Therefore, CEA and TEM- 8 mRNA copy numbers can be introduced as markers of tumor progression among the Iranian CRC patients [154].

\section{Conclusion}

It has been shown that the ethnic is an important issue in genetic abnormalities that are involved in tumor progression. For the first time, present review summarizes all of the genetic and epigenetic factors which are reported in CRC until now among the Iranian patients to pave the way of incorporation of new ethnic specific markers into the clinical practice and development of new targeted therapeutic options.

\section{Abbreviations \\ CEA: Carcinoembryonic antigen; CRC: Colorectal carcinoma; CSCs: Cancer stem cells; CTAs: Cancer-Testis antigens; CTLA-4: Cytotoxic T-lymphocyte antigen-4; EMT: Epithelial-mesenchymal transition; GSTs: Glutathione S- transferases; HATs: Histone acetyltransferases; HDACs: Histone deacetylases; IRS1: Insulin receptor substrate 1; MDR: Multi drug resistance; MGMT: O6- methylguanine DNA methyltransferase; MMR: Mismatch repair; MTHFR: Methylenetetrahydrofolate reductase; NEBL: Nebulin; NO: Nitric oxide; NOS: Nitric oxide synthase; PB: Peripheral blood; PKA: Protein kinase A; SEPT9: Septin 9; TEM-8: Tumor epithelial marker 8; TGF-b: Transforming growth factor b; UPS: Ubiquitin-proteasome system}

\section{Acknowledgements}

Not applicable.

\section{Funding}

Not applicable.

\section{Availability of data and materials}

The datasets used and/or analyzed during the current study are available from the corresponding author on reasonable request.
Authors' contributions

MRA and MM prepared and edited the draft. All authors read and approved the final manuscript.

Ethics approval and consent to participate

Not applicable.

\section{Consent for publication}

Not applicable.

Competing interests

The authors declare that they have no competing interests.

\section{Publisher's Note}

Springer Nature remains neutral with regard to jurisdictional claims in published maps and institutional affiliations.

\section{Author details}

${ }^{1}$ Medical Genetics Research Center, Mashhad University of Medical Sciences, Mashhad, Iran. ${ }^{2}$ Department of Modern Sciences and Technologies, Faculty

of Medicine, Mashhad University of Medical Sciences, Mashhad, Iran.

Received: 20 October 2018 Accepted: 5 December 2018

Published online: 22 December 2018

References

1. Ansari $R$, et al. Incidence and age distribution of colorectal cancer in Iran: results of a population-based cancer registry. Cancer Lett. 2006;240(1):143-7.

2. Hosseini SV, Izadpanah A, Yarmohammadi H. Epidemiological changes in colorectal cancer in shiraz, Iran: 1980-2000. ANZ J Surg. 2004;74(7):547-9.

3. Morimoto $L M$, et al. Risk factors for hyperplastic and adenomatous polyps: evidence for malignant potential? Cancer Epidemiol Biomark Prev. 2002; 11(10 Pt 1):1012-8.

4. Dawson MA, Kouzarides T. Cancer epigenetics: from mechanism to therapy. Cell. 2012;150(1):12-27.

5. You JS, Jones PA. Cancer genetics and epigenetics: two sides of the same coin? Cancer Cell. 2012;22(1):9-20.

6. Ting WC, et al. Common genetic variants in Wnt signaling pathway genes as potential prognostic biomarkers for colorectal cancer. PLoS One. 2013; 8(2):e56196.

7. Yokota T. Are KRAS/BRAF mutations potent prognostic and/or predictive biomarkers in colorectal cancers? Anti Cancer Agents Med Chem. 2012; 12(2):163-71.

8. Jovov B, et al. Differential gene expression between African American and European American colorectal cancer patients. PLoS One. 2012;7(1):e30168.

9. Peters $\mathrm{WH}$, et al. Biotransformation enzymes in human intestine: critical low levels in the colon? Gut. 1991:32(4):408-12.

10. Kihara M, Kihara M, Noda K. Risk of smoking for squamous and small cell carcinomas of the lung modulated by combinations of CYP1A1 and GSTM1 gene polymorphisms in a Japanese population. Carcinogenesis. 1995;16(10): 2331-6.

11. Nebert DW, McKinnon RA, Puga A. Human drug-metabolizing enzyme polymorphisms: effects on risk of toxicity and cancer. DNA Cell Biol. 1996; 15(4):273-80.

12. Singhal SS, et al. Induction of glutathione S-transferase hGST 5.8 is an early response to oxidative stress in RPE cells. Invest Ophthalmol Vis Sci. 1999; 40(11):2652-9.

13. Vanhaecke $T$, et al. Effect of ethanol on the expression of hepatic glutathione S-transferase: an in vivo/in vitro study. Biochem Pharmacol. 2000;60(10):1491-6.

14. Nomani $\mathrm{H}$, et al. Glutathione S-transferases activity in patients with colorectal cancer. Clin Biochem. 2005:38(7):621-4.

15. Ebrahimkhani S, et al. Association of GSTM1, GSTT1, GSTP1 and CYP2E1 single nucleotide polymorphisms with colorectal cancer in Iran. Pathol Oncol Res. 2012:18(3):651-6.

16. Jamhiri I, Saadat I, Omidvari S. Genetic polymorphisms of superoxide dismutase-1 A251G and catalase C-262T with the risk of colorectal cancer. Mol Biol Res Commun. 2017;6(2):85-90.

17. Bassermann F, Pagano M. Dissecting the role of ubiquitylation in the DNA damage response checkpoint in G2. Cell Death Differ. 2010;17(1):78-85. 
18. van Wijk SJ, Timmers HT. The family of ubiquitin-conjugating enzymes (E2s): deciding between life and death of proteins. FASEB J. 2010;24(4):981-93.

19. Mokarram $P$, et al. Promoter methylation status of two novel human genes, UBE2Q1 and UBE2Q2, in colorectal Cancer: a new finding in Iranian patients. Asian Pac J Cancer Prev. 2015;16(18):8247-52.

20. Massague J. TGFbeta in Cancer. Cell. 2008;134(2):215-30.

21. Derynck R, Akhurst RJ, Balmain A. TGF-beta signaling in tumor suppression and cancer progression. Nat Genet. 2001;29(2):117-29.

22. Amirghofran $Z$, et al. Genetic polymorphism in the transforming growth factor beta1 gene ( $-509 \mathrm{C} / \mathrm{T}$ and $-800 \mathrm{G} / \mathrm{a})$ and colorectal cancer. Cancer Genet Cytogenet. 2009;190(1):21-5.

23. Akbari Z, et al. Lack of influence of the SMAD7 gene rs2337107 polymorphism on risk of colorectal cancer in an Iranian population. Asian Pac J Cancer Prev. 2014;15(11):4437-41.

24. Damavand $B$, et al. Intronic polymorphisms of the SMAD7 gene in association with colorectal cancer. Asian Pac J Cancer Prev. 2015;16(1):41-4.

25. Moghbeli M, et al. Role of Msi1 and PYGO2 in esophageal squamous cell carcinoma depth of invasion. J Cell Commun Signal. 2016;10(1):49-53.

26. Kimelman D, Xu W. Beta-catenin destruction complex: insights and questions from a structural perspective. Oncogene. 2006;25(57):7482-91.

27. Giles $\mathrm{RH}$, van Es JH, Clevers H. Caught up in a Wnt storm: Wnt signaling in cancer. Biochim Biophys Acta. 2003;1653(1):1-24.

28. Thorstensen $L$, et al. Genetic and epigenetic changes of components affecting the WNT pathway in colorectal carcinomas stratified by microsatellite instability. Neoplasia. 2005;7(2):99-108.

29. Naghibalhossaini F, et al. Epigenetic and genetic analysis of WNT signaling pathway in sporadic colorectal cancer patients from Iran. Mol Biol Rep. 2012;39(5):6171-8

30. Samaei NM, et al. Promoter methylation analysis of WNT/beta-catenin pathway regulators and its association with expression of DNMT1 enzyme in colorectal cancer. J Biomed Sci. 2014;21:73.

31. Naini MA, et al. Sensitive and noninvasive detection of aberrant SFRP2 and MGMT-B methylation in Iranian patients with Colon polyps. Asian Pac J Cancer Prev. 2016;17(4):2185-93.

32. Rakoff-Nahoum S. Why cancer and inflammation? Yale J Biol Med. 2006; 79(3-4):123-30.

33. Shi $Y$, et al. The role of interleukin-17A in colorectal tumorigenesis. Cancer Biother Radiopharm. 2013;28(6):429-32.

34. Nemati K, et al. Interleukin-17FT7488 allele is associated with a decreased risk of colorectal cancer and tumor progression. Gene. 2015;561(1):88-94.

35. Aukrust $P$, et al. Inflammatory and anti-inflammatory cytokines in chronic heart failure: potential therapeutic implications. Ann Med. 2005;37(2):74-85.

36. Feghali CA, Wright TM. Cytokines in acute and chronic inflammation. Front Biosci. 1997;2:d12-26.

37. van Horssen $\mathrm{R}$, Ten Hagen $\mathrm{TL}$, Eggermont AM. TNF-alpha in cancer treatment: molecular insights, antitumor effects, and clinical utility. Oncologist. 2006;11(4):397-408

38. Azimzadeh P, et al. Interleukin-16 (IL-16) gene polymorphisms in Iranian patients with colorectal cancer. J Gastrointestin Liver Dis. 2011;20(4):371-6.

39. Al-Samadi A, et al. Distinctive expression pattern of interleukin-17 cytokine family members in colorectal cancer. Tumour Biol. 2016;37(2):1609-15.

40. Tian Y, et al. Differential effects of NOD2 polymorphisms on colorectal cancer risk: a meta-analysis. Int J Color Dis. 2010;25(2):161-8.

41. Landi $D$, et al. Polymorphisms within micro-RNA-binding sites and risk of sporadic colorectal cancer. Carcinogenesis. 2008;29(3):579-84

42. Ahangari $F$, et al. A miRNA-binding site single nucleotide polymorphism in the 3'-UTR region of the NOD2 gene is associated with colorectal cancer. Med Oncol. 2014;31(9):173.

43. Azimzadeh $\mathrm{P}$, et al. Association of co-stimulatory human B-lymphocyte antigen B7-2 (CD86) gene polymorphism with colorectal cancer risk. Gastroenterol Hepatol Bed Bench. 2013;6(2):86-91.

44. Abtahi $S$, et al. Dual association of serum interleukin-10 levels with colorectal cancer. J Cancer Res Ther. 2017;13(2):252-6.

45. Jaiswal M, LaRusso NF, Gores GJ. Nitric oxide in gastrointestinal epithelial cell carcinogenesis: linking inflammation to oncogenesis. Am J Physiol Gastrointest Liver Physiol. 2001;281(3):G626-34

46. Kim PK, et al. The regulatory role of nitric oxide in apoptosis. Int Immunopharmacol. 2001;1(8):1421-41.

47. Kobzik L, et al. Nitric oxide in skeletal muscle. Nature. 1994;372(6506):546-8.

48. Weinberg JB. Nitric oxide synthase 2 and cyclooxygenase 2 interactions in inflammation. Immunol Res. 2000;22(2-3):319-41.
49. Habibollahi $P$, et al. Correlation between inducible nitric oxide synthase and cyclooxygenase-2 expression in human colorectal adenocarcinoma: a crosssectional study. Pathol Oncol Res. 2010;16(3):327-35.

50. Tivol EA, et al. Loss of CTLA-4 leads to massive lymphoproliferation and fatal multiorgan tissue destruction, revealing a critical negative regulatory role of CTLA-4. Immunity. 1995;3(5):541-7.

51. Walunas TL, Bakker CY, Bluestone JA. CTLA-4 ligation blocks CD28dependent T cell activation. J Exp Med. 1996;183(6):2541-50.

52. Hadinia A, et al. CTLA-4 gene promoter and exon 1 polymorphisms in Iranian patients with gastric and colorectal cancers. J Gastroenterol Hepatol. 2007;22(12):2283-7.

53. Shafaei $\mathrm{S}$, et al. The association between CD166 detection rate and clinicopathologic parameters of patients with colorectal cancer. Caspian J Intern Med. 2013;4(4):768-72.

54. Nishida M, Funahashi T, Shimomura I. Pathophysiological significance of adiponectin. Med Mol Morphol. 2007;40(2):55-67.

55. Sugiyama $M$, et al. Adiponectin inhibits colorectal cancer cell growth through the AMPK/mTOR pathway. Int J Oncol. 2009;34(2):339-44.

56. Mahmoudi T, et al. Association of adiponectin receptor 1 gene - 106 C > T variant with susceptibility to colorectal cancer. Meta Gene. 2016;9:210-4.

57. Albanell J, et al. Activated extracellular signal-regulated kinases: association with epidermal growth factor receptor/transforming growth factor alpha expression in head and neck squamous carcinoma and inhibition by antiepidermal growth factor receptor treatments. Cancer Res. 2001;61(17): 6500-10.

58. Motlagh A, et al. Expression of epidermal growth factor receptor as a predictive factor for rectal cancer. Arch Iran Med. 2007;10(3):301-8.

59. Tavangar SM, Shariftabrizi A, Soroush AR. Her-2/neu over-expression correlates with more advanced disease in Iranian colorectal cancer patients. Med Sci Monit. 2005:11(3):CR123-6.

60. Liu $L$, et al. A novel protein tyrosine kinase NOK that shares homology with platelet- derived growth factor/fibroblast growth factor receptors induces tumorigenesis and metastasis in nude mice. Cancer Res. 2004;64(10):3491-9.

61. Orang AV, et al. Diagnostic relevance of overexpressed serine threonine tyrosine kinase/novel oncogene with kinase domain (STYK1/ NOK) mRNA in colorectal cancer. Asian Pac J Cancer Prev. 2014;15(16):6685-9.

62. John $\mathrm{T}$, et al. The role of Cancer-testis antigens as predictive and prognostic markers in non-small cell lung cancer. PLoS One. 2013;8(7):e67876.

63. Tavakoli Koudehi A, et al. AKAP4, SPAG9 and NY-ESO-1 in Iranian colorectal Cancer patients as probable diagnostic and prognostic biomarkers. Asian Pac J Cancer Prev. 2018;19(2):463-9.

64. Lee $\mathrm{S}$, et al. Clinicopathological features of $\mathrm{CpG}$ island methylator phenotype-positive colorectal cancer and its adverse prognosis in relation to KRAS/BRAF mutation. Pathol Int. 2008;58(2):104-13.

65. Hamzehzadeh $L$, et al. Common KRAS and NRAS gene mutations in sporadic colorectal cancer in northeastern Iranian patients. Curr Probl Cancer. 2018:42(6):572-81.

66. Fransen $\mathrm{K}$, et al. Mutation analysis of the BRAF, ARAF and RAF-1 genes in human colorectal adenocarcinomas. Carcinogenesis. 2004:25(4):527-33.

67. Guedes JG, et al. High resolution melting analysis of KRAS, BRAF and PIK3CA in KRAS exon 2 wild-type metastatic colorectal cancer. BMC Cancer. 2013;13:169.

68. Koochak A, et al. Mutation analysis of KRAS and BRAF genes in metastatic colorectal Cancer: a first large scale study from Iran. Asian Pac J Cancer Prev. 2016;17(2):603-8

69. Omidifar NM, Geramizadeh BM, Mirzai MM. K-ras mutation in colorectal Cancer, a report from southern Iran. Iran J Med Sci. 2015:40(5):454-60.

70. Zhao R, et al. Analysis of p53-regulated gene expression patterns using oligonucleotide arrays. Genes Dev. 2000;14(8):981-93.

71. Ghavam-Nasiri MR, et al. Expression of p53 in colorectal carcinoma: correlation with clinicopathologic features. Arch Iran Med. 2007;10(1):38-42.

72. Sternberg MJ, et al. Progress in protein structure prediction: assessment of CASP3. Curr Opin Struct Biol. 1999;9(3):368-73.

73. Zheng $\mathrm{HC}$, et al. Expression of Fas ligand and caspase-3 contributes to formation of immune escape in gastric cancer. World J Gastroenterol. 2003; 9(7):1415-20.

74. Asadi M, et al. Expression level of caspase genes in colorectal Cancer. Asian Pac J Cancer Prev. 2018:19(5):1277-80.

75. Golmohammadi R, et al. Characterization and prognostic value of mutations in exons 5 and 6 of the p53 gene in patients with colorectal cancers in Central Iran. Gut Liver. 2013;7(3):295-302. 
76. Atoum MF, Tchoporyan MN. Association between circulating vitamin D, the Taq1 vitamin D receptor gene polymorphism and colorectal cancer risk among Jordanians. Asian Pac J Cancer Prev. 2014;15(17):7337-41.

77. Moossavi $\mathrm{M}$, et al. Positive correlation between vitamin $\mathrm{D}$ receptor gene Fokl polymorphism and colorectal cancer susceptibility in South-Khorasan of Iran. J Cell Biochem. 2018;119(10):8190-4.

78. Mahmoudi T, et al. Vitamin D receptor gene Apal polymorphism is associated with susceptibility to colorectal cancer. Dig Dis Sci. 2010;55(7):2008-13.

79. Limburg PJ, et al. Insulin, glucose, insulin resistance, and incident colorectal cancer in male smokers. Clin Gastroenterol Hepatol. 2006;4(12):1514-21.

80. Larsson SC, Orsini N, Wolk A. Diabetes mellitus and risk of colorectal cancer: a meta-analysis. J Natl Cancer Inst. 2005;97(22):1679-87.

81. Reuveni $\mathrm{H}$, et al. Therapeutic destruction of insulin receptor substrates for cancer treatment. Cancer Res. 2013;73(14):4383-94

82. Mahmoudi T, et al. Gly972Arg variant of insulin receptor substrate 1 gene and colorectal cancer risk in overweight/obese subjects. Int J Biol Markers. 2016;31(1):e68-72.

83. Hua FF, et al. MiRNA-338-3p regulates cervical cancer cells proliferation by targeting MACC1 through MAPK signaling pathway. Eur Rev Med Pharmacol Sci. 2017;21(23):5342-52.

84. Bian $\mathrm{X}$, et al. HDAC inhibitor suppresses proliferation and invasion of breast cancer cells through regulation of miR-200c targeting CRKL. Biochem Pharmacol. 2018;147:30-7.

85. Mahdavinezhad A, et al. Evaluation of miR-141, miR-200c, miR-30b expression and Clinicopathological features of bladder Cancer. Int J Mol Cell Med. 2015:4(1):32-9.

86. Karimi Mazraehshah $\mathrm{M}$, et al. Anticancer effects of miR-200c in colorectal cancer through BMI1. J Cell Biochem. 2018;119(12):10005-12.

87. Greene SB, et al. A putative role for microRNA-205 in mammary epithelial cell progenitors. J Cell Sci. 2010;123(Pt 4):606-18.

88. Qin AY, et al. MiR-205 in cancer: an angel or a devil? Eur J Cell Biol. 2013; 92(2):54-60.

89. Zhao BS, et al. Screening of microRNA in patients with esophageal cancer at same tumor node metastasis stage with different prognoses. Asian Pac J Cancer Prev. 2013;14(1):139-43.

90. Orang AV, et al. Diagnostic and prognostic value of miR-205 in colorectal cancer. Asian Pac J Cancer Prev. 2014;15(9):4033-7.

91. Basati $G$, et al. Elevated level of microRNA-21 in the serum of patients with colorectal cancer. Med Oncol. 2014;31(10):205.

92. Bastaminejad S, et al. Investigation of MicroRNA-21 expression levels in serum and stool as a potential non-invasive biomarker for diagnosis of colorectal Cancer. Iran Biomed J. 2017;21(2):106-13.

93. Poudyal D, et al. A key role of microRNA-29b for the suppression of colon cancer cell migration by American ginseng. PLoS One. 2013:8(10):e75034.

94. Xiao $L$, et al. miR-29b represses intestinal mucosal growth by inhibiting translation of cyclin-dependent kinase 2. Mol Biol Cell. 2013;24(19):3038-46.

95. Basati $G$, et al. Circulating levels of the miRNAs, miR-194, and miR-29b, as clinically useful biomarkers for colorectal cancer. Tumour Biol. 2016;37(2): 1781-8.

96. Hur K, et al. MicroRNA-200c modulates epithelial-to-mesenchymal transition (EMT) in human colorectal cancer metastasis. Gut. 2013;62(9):1315-26.

97. Paterson $E L$, et al. Down-regulation of the miRNA-200 family at the invasive front of colorectal cancers with degraded basement membrane indicates EMT is involved in cancer progression. Neoplasia. 2013;15(2):180-91.

98. Khalili $\mathrm{M}$, et al. Downregulation of the genes involved in reprogramming (SOX2, c-MYC, miR-302, miR-145, and P21) in gastric adenocarcinoma. J Gastrointest Cancer. 2015:46(3):251-8.

99. Li S, et al. miR-145 suppresses colorectal cancer cell migration and invasion by targeting an ETS-related gene. Oncol Rep. 2016;36(4):1917-26.

100. Valeri $\mathrm{N}$, et al. MicroRNA-135b promotes cancer progression by acting as a downstream effector of oncogenic pathways in colon cancer. Cancer Cell. 2014;25(4):469-83.

101. Cottonham CL, Kaneko S, Xu L. miR-21 and miR-31 converge on TIAM1 to regulate migration and invasion of colon carcinoma cells. J Biol Chem. 2010; 285(46):35293-302.

102. Sun D, et al. MicroRNA-31 activates the RAS pathway and functions as an oncogenic MicroRNA in human colorectal cancer by repressing RAS p21 GTPase activating protein 1 (RASA1). J Biol Chem. 2013;288(13):9508-18.

103. Xu T, et al. microRNA-20a enhances the epithelial-to-mesenchymal transition of colorectal cancer cells by modulating matrix metalloproteinases. Exp Ther Med. 2015;10(2):683-8.
104. Zhang GJ, et al. miR20a is an independent prognostic factor in colorectal cancer and is involved in cell metastasis. Mol Med Rep. 2014;10(1):283-91.

105. Eslamizadeh $\mathrm{S}$, et al. The role of MicroRNA signature as diagnostic biomarkers in different clinical stages of colorectal Cancer. Cell J. 2018;20(2): 220-30.

106. Soreide $\mathrm{K}$, et al. Microsatellite instability in colorectal cancer. Br J Surg. 2006 93(4):395-406

107. Montazer Haghighi M, et al. Four novel germline mutations in the MLH1 and PMS2 mismatch repair genes in patients with hereditary nonpolyposis colorectal cancer. Int J Color Dis. 2009;24(8):885-93.

108. Shahmoradi S, et al. Two novel mutations in hMLH1 gene in Iranian hereditary non-polyposis colorectal cancer patients. Familial Cancer. 2012; 11(1):13-7.

109. Boland CR, et al. A National Cancer Institute workshop on microsatellite instability for cancer detection and familial predisposition: development of international criteria for the determination of microsatellite instability in colorectal cancer. Cancer Res. 1998;58(22):5248-57.

110. Moghbeli $M$, et al. High frequency of microsatellite instability in sporadic colorectal cancer patients in Iran. Genet Mol Res. 2011;10(4):3520-9.

111. Faghani $M$, et al. The correlation between microsatellite instability and the features of sporadic colorectal Cancer in the north part of Iran. Gastroenterol Res Pract. 2012;2012:756263.

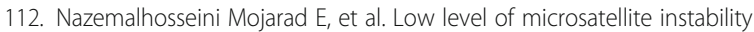
correlates with poor clinical prognosis in stage II colorectal Cancer patients. J Oncol. 2016;2016:2196703.

113. Brim $\mathrm{H}$, et al. Impact of BRAF, MLH1 on the incidence of microsatellite instability high colorectal cancer in populations based study. Mol Cancer. 2008;7:68

114. Khatami F, et al. Effects of amino acid substitution polymorphisms of two DNA methyltransferases on susceptibility to sporadic colorectal cancer. Asian Pac J Cancer Prev. 2009;10(6):1183-8.

115. Farzanehfar $M$, et al. Evaluation of methylation of MGMT (O(6)methylguanine-DNA methyltransferase) gene promoter in sporadic colorectal cancer. DNA Cell Biol. 2013;32(7):371-7.

116. Glozak MA, Seto E. Histone deacetylases and cancer. Oncogene. 2007;26(37): 5420-32.

117. Nemati $M$, et al. Deregulated expression of HDAC3 in colorectal cancer and its clinical significance. Adv Clin Exp Med. 2018;27(3):305-11.

118. Frank D, Doenecke D, Albig W. Differential expression of human replacement and cell cycle dependent H3 histone genes. Gene. 2003;312:135-43.

119. Jang CW, et al. Histone $\mathrm{H} 3.3$ maintains genome integrity during mammalian development. Genes Dev. 2015;29(13):1377-92.

120. Fang JY, Richardson BC. The MAPK signalling pathways and colorectal cancer. Lancet Oncol. 2005;6(5):322-7.

121. Ayoubi HA, Mahjoubi F, Mirzaei R. Investigation of the human H3.3B (H3F3B) gene expression as a novel marker in patients with colorectal cancer. J Gastrointest Oncol. 2017:8(1):64-9.

122. Wei YH, Lee HC. Oxidative stress, mitochondrial DNA mutation, and impairment of antioxidant enzymes in aging. Exp Biol Med (Maywood). 2002;227(9):671-82.

123. Akouchekian $M$, et al. High rate of mutation in mitochondrial DNA displacement loop region in human colorectal cancer. Dis Colon Rectum. 2009:52(3):526-30

124. Sternberg D, et al. Exhaustive scanning approach to screen all the mitochondrial tRNA genes for mutations and its application to the investigation of 35 independent patients with mitochondrial disorders. Hum Mol Genet. 1998;7(1):33-42.

125. Mohammed F, et al. Mitochondrial A12308G alteration in tRNA(Leu(CUN)) in colorectal cancer samples. Diagn Pathol. 2015;10:115.

126. Kim YI. Folate and carcinogenesis: evidence, mechanisms, and implications. J Nutr Biochem. 1999;10(2):66-88.

127. Shrubsole MJ, et al. Dietary folate intake and breast cancer risk: results from the Shanghai breast Cancer study. Cancer Res. 2001;61(19):7136-41.

128. Haghighi MM, et al. Association between the 1793G> a MTHFR polymorphism and sporadic colorectal cancer in Iran. Asian Pac J Cancer Prev. 2008:9(4):659-62.

129. McCann SE, et al. Diet in the epidemiology of endometrial cancer in western New York (United States). Cancer Causes Control. 2000;11(10):965-74.

130. Rampersaud GC, et al. Genomic DNA methylation decreases in response to moderate folate depletion in elderly women. Am J Clin Nutr. 2000:72(4): 998-1003. 
131. Naghibalhossaini F, et al. MTHFR C677T and A1298C variant genotypes and the risk of microsatellite instability among Iranian colorectal cancer patients. Cancer Genet Cytogenet. 2010;197(2):142-51.

132. Leonard GD, Fojo T, Bates SE. The role of ABC transporters in clinical practice. Oncologist. 2003;8(5):411-24.

133. Luqmani YA. Mechanisms of drug resistance in cancer chemotherapy. Med Princ Pract. 2005;14(Suppl 1):35-48.

134. Petrova DT, et al. No association between MDR1 (ABCB1) 2677G>T and $3435 \mathrm{C}>$ T polymorphism and sporadic colorectal cancer among Bulgarian patients. J Cancer Res Clin Oncol. 2008;134(3):317-22.

135. Arceci RJ. Clinical significance of P-glycoprotein in multidrug resistance malignancies. Blood. 1993;81(9):2215-22.

136. Samanian S, et al. MDR1 gene polymorphisms: possible association with its expression and clinicopathology characteristics in colorectal cancer patients. Asian Pac J Cancer Prev. 2011:12(11):3141-5.

137. Khedri A, et al. Association of the colorectal cancer and MDR1 gene polymorphism in an Iranian population. Mol Biol Rep. 2011;38(5):2939-43.

138. Ardalan Khales S, et al. SALL4 as a new biomarker for early colorectal cancers. J Cancer Res Clin Oncol. 2015;141(2):229-35.

139. Monk M, Hitchins M, Hawes S. Differential expression of the embryo/cancer gene ECSA (DPPA2), the cancer/testis gene BORIS and the pluripotency structural gene OCT4, in human preimplantation development. Mol Hum Reprod. 2008;14(6):347-55.

140. Monk M, Holding C. Human embryonic genes re-expressed in cancer cells. Oncogene. 2001;20(56):8085-91.

141. Hutvagner G, Simard MJ. Argonaute proteins: key players in RNA silencing. Nat Rev Mol Cell Biol. 2008;9(1):22-32.

142. Seto AG, Kingston RE, Lau NC. The coming of age for Piwi proteins. Mol Cell. 2007;26(5):603-9.

143. Raeisossadati R, et al. Aberrant expression of DPPA2 and HIWI genes in colorectal cancer and their impacts on poor prognosis. Tumour Biol. 2014; 35(6):5299-305.

144. Spillane JB, Henderson MA. Cancer stem cells: a review. ANZ J Surg. 2007; 77(6):464-8

145. Moghbeli M, et al. Cancer stem cell detection and isolation. Med Oncol. 2014;31(9):69.

146. Mirzaei A, et al. Upregulation of circulating cancer stem cell marker, DCLK1 but not Lgr5, in chemoradiotherapy-treated colorectal cancer patients. Tumour Biol. 2015;36(6):4801-10.

147. Micalizzi DS, Ford HL. Epithelial-mesenchymal transition in development and cancer. Future Oncol. 2009:5(8):1129-43.

148. Ogrodnik M, et al. Dynamic JUNQ inclusion bodies are asymmetrically inherited in mammalian cell lines through the asymmetric partitioning of vimentin. Proc Natl Acad Sci U S A. 2014;111(22):8049-54.

149. Niknami $Z$, et al. The association of vimentin and fibronectin gene expression with epithelial-mesenchymal transition and tumor malignancy in colorectal carcinoma. EXCLI J. 2017;16:1009-17.

150. Hosseini SM, et al. Nebulette expression is associated with lymph node metastasis in patients with colorectal Cancer. Middle East J Dig Dis. 2018; 10(3):174-9.

151. Estey MP, Kim MS, Trimble WS. Septins. Curr Biol. 2011;21(10):R384-7.

152. Sandrock K, et al. Characterization of human septin interactions. Biol Chem. 2011;392(8-9):751-61.

153. Behrouz Sharif $\mathrm{S}$, et al. Detection of aberrant methylated SEPT9 and NTRK3 genes in sporadic colorectal cancer patients as a potential diagnostic biomarker. Oncol Lett. 2016;12(6):5335-43.

154. Raeisossadati R, et al. Quantitative analysis of TEM-8 and CEA tumor markers indicating free tumor cells in the peripheral blood of colorectal cancer patients. Int J Color Dis. 2011;26(10):1265-70.

Ready to submit your research? Choose BMC and benefit from:

- fast, convenient online submission

- thorough peer review by experienced researchers in your field

- rapid publication on acceptance

- support for research data, including large and complex data types

- gold Open Access which fosters wider collaboration and increased citations

- maximum visibility for your research: over $100 \mathrm{M}$ website views per year

At BMC, research is always in progress.

Learn more biomedcentral.com/submissions 